\title{
USING PBEE TO ASSESS AND IMPROVE PERFORMANCE OF DIFFERENT STRUCTURAL SYSTEMS FOR LOW-RISE STEEL BUILDINGS
}

\author{
VESNA TERZIC ${ }^{1} \&$ STEPHEN A. MAHIN ${ }^{2}$ \\ ${ }^{1}$ Civil Engineering and Construction Management, California State University Long Beach, California, USA. \\ ${ }^{2}$ Civil and Environmental Engineering, University of California Berkeley, California, USA.
}

\begin{abstract}
In recent earthquakes in Chile, New Zealand, and Japan modern buildings were generally quite safe. However, there was a tremendous variability in the economic and social consequences associated with damage repair and loss of occupancy. Code-compliant structures are generally designed to provide safety and prevent collapse at minimum costs, but when severe ground shaking occurs, the damage to contents, nonstructural components and the structural system can result in loss of function, which can have a dramatic impact on the occupants, owners, and community. Such situations can be avoided by mitigating future seismic damage through a better structural design. Although structural enhancements may likely increase the initial cost of a structure they should be compensated through benefits realized over its lifetime. This paper presents the results of repair cost and repair time analyses of conventional and high-performance code-compliant low-rise commercial steel buildings designed for the same location. The buildings are located at a site with high seismic hazard representative of western North America. The conventional lateral load-resisting systems include: special moment resisting frame, special concentrically braced frame, and buckling restrained braced frame; and high-performance systems include: seismically isolated intermediate moment resisting frame, seismically isolated ordinary concentrically braced frame, seismically isolated buckling restrained braced frame, and viscously damped moment frame. In addition, enhancements of the fixed, seismically isolated, and viscously damped moment frames beyond the code minimum and their effect on the repair cost and repair time are studied. The analysis reveals significant damage savings for code-compliant seismically isolated systems relative to their conventional counterpart, with seismically isolated ordinary concentrically braced frames yielding the largest savings. It also shows that enhancements of the isolation and viscously damped system beyond code minimum standards results in significant reduction in damage-induced losses, while the enhancement of the SMRF does not yield desirable loss reduction.
\end{abstract}

Keywords: Base isolation, braced frames, dampers, moment resisting frames, repair loss, repair time.

\section{INTRODUCTION}

The aim of building codes is to design structures that achieve functional requirements with adequate safety but at a minimum cost. As evidenced by the M8.8 27 February 2010 Chile earthquake, the tremendous variation in consequences associated with damage, repair, and loss of occupancy of the modern buildings was observed. While some of the buildings had minimal damage, great number of buildings experienced considerable damage to nonstructural and structural components, resulting in not only a large economic loss in terms of repair costs but also incurred an additional financial burden associated with the loss of function due to necessity of performing these extensive repairs [1].

Earthquake hazards and risks can be systematically characterized through performance-based earthquake evaluation (PBEE) methodologies. This paper has employed PBEE methods developed by the Pacific Earthquake Engineering Research Center (PEER) [2] adopted for general use in FEMA P-58 [3] to evaluate the repair cost and repair time of conventional, high-performance, and enhanced (i.e., beyond minimum requirements) structural designs for a low-rise commercial steel building. The conventional steel lateral load-resisting 
systems include: special moment resisting frame (SMRF), special concentrically braced frame (SCBF), and buckling restrained braced frame (BRBF); high-performance systems include: base-isolated intermediate moment resisting frame (BI-IMRF), base-isolated ordinary concentrically braced frame (BI-OCBF), base-isolated buckling restrained braced frame (BI-BRBF), and viscously damped moment frame (VDMF); enhanced systems include beyond the code minimum designs of: SMRF, BI-IMRF, and VDMF, designated as SMRFe, BI-IMRFe, and VDMFe. The conventional and high-performance buildings are designed to satisfy close to minimum code requirements for a site with high seismic hazard representative of western North America. The performance of the considered building designs is evaluated and compared for three seismic hazard levels: $2 \%, 10 \%$, and $50 \%$ probabilities of exceedance in 50 years (referred to as $2 \%$ in 50-year, $10 \%$ in 50-year, and $50 \%$ in 50-year).

This paper illustrates the ability of simplified PBEE procedures to identify cost-effective strategies for reducing earthquake-induced costs during the preliminary stages of seismic design. To aid understanding of the relative performance of the considered systems, median values of key engineering demand parameters (EDPs) (i.e., maximum and residual interstory drifts and floor accelerations) are compared at different hazard levels. The paper further highlights the factors that contribute significantly to the economic losses and the ability of high-performance or enhanced structural systems in reducing these losses.

\section{WORKFLOW ANALYSIS WITHIN PBEE FRAMEWORK}

The workflow analysis within PBEE framework necessary for evaluation of repair cost and repair time is presented herein. The hazard model and ground motion selections for the considered site were adopted from Baker et al. [4]. These ground motions were used in conjunction with nonlinear numerical models of different building configurations that simulated the full range of responses that the facility might experience throughout its lifetime. The computer software OpenSees [5] was utilized to perform the numerical simulations. Engineering demand parameters were monitored during the numerical simulations and used in conjunction with PACT [6] to calculate cost and time needed to repair each damaged component (structural and non-structural) for each realization of Monte Carlo simulations at every considered hazard level. The repair costs for all components of the building at one hazard level were summed for each realization to obtain the cumulative distribution function of the repair cost for that hazard level. To estimate the cumulative distribution function of the repair time for a specified hazard level, the repair times of components along with their damage states and number of damaged units were used in conjunction with the repair time model developed by Terzic et al. [7]. Cost and time needed for a building repair is presented utilizing the median and 90th percentile outcomes.

\subsection{Building configurations}

The study considered a three-story steel office building located on a site representative of the high seismic hazard characteristic of western North America. The basic building plan dimensions are $120 \mathrm{ft} \times 180 \mathrm{ft}$, with a bay spacing of $30 \mathrm{ft}$ in each direction and a typical story height of $15 \mathrm{ft}$, with the exception of the first story height of $17 \mathrm{ft}$ for SMRFs and VDMFs. The building is located on stiff soil (site class D with reference shear wave velocity $=180$ to $360 \mathrm{~m} / \mathrm{s}$ ). Code spectral accelerations were selected to be $S_{\mathrm{s}}=2.2 \mathrm{~g}$ for short periods and $\mathrm{S}_{1}=0.74 \mathrm{~g}$ at a period of $1 \mathrm{sec}$, which are representative of many locations in California.

All systems were designed by professional engineers to meet minimum code standards for design according to the Equivalent Lateral Force Method [8]. Building configurations and specifications are provided in Fig. 1 and Table 1. The fixed base and base-isolated 
moment resisting and concentrically braced frames were designed by Forell/Elsesser Engineers, Inc [9], Miyamoto International designed VDMFs, Ugljesa Terzic S.E. designed fixed base and base-isolated BRBF, and the authors designed the enhanced versions of SMRF and BI-IMRF.

SMRF and BI-IMRF.

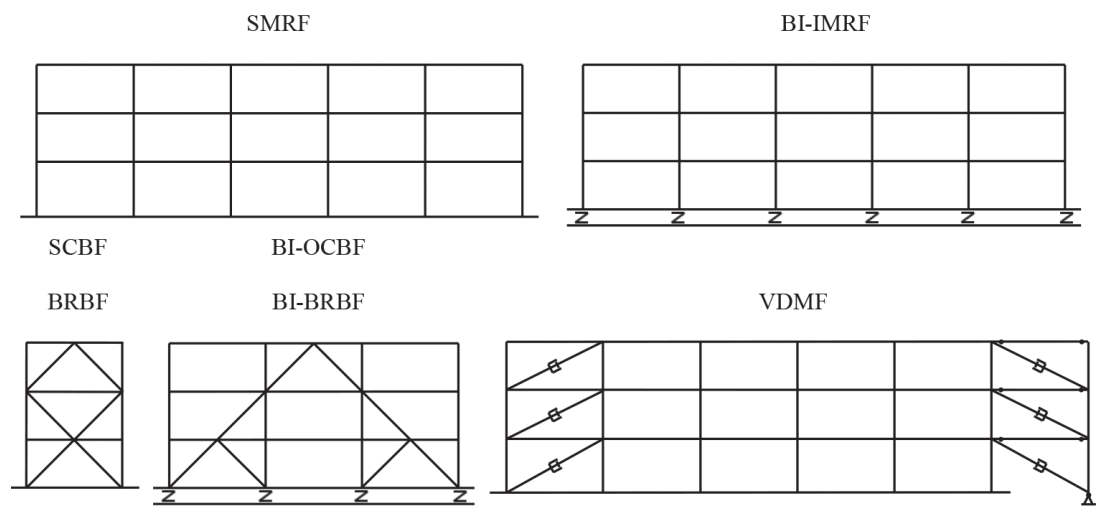

Figure 1: Configurations of different lateral load-resisting systems.

Table 1: Beam, column, and brace sizes of different lateral load-resisting systems.

\begin{tabular}{|c|c|c|c|c|c|}
\hline Systems & Elements & Base & Story 1 & Story 2 & Roof \\
\hline \multirow[t]{2}{*}{ SMRF } & Beams & - & W33x141 & W33x130 & W102x102 \\
\hline & Columns & - & W14x370 & $\mathrm{W} 14 \times 370$ & W14x211 \\
\hline \multirow[t]{2}{*}{ SMRFe } & Beams & - & $\mathrm{W} 14 \times 500$ & $\mathrm{~W} 14 \times 500$ & $\mathrm{~W} 14 \times 370$ \\
\hline & Columns & - & W36x182 & W36x182 & W33x130 \\
\hline \multirow[t]{2}{*}{ BI-IMRF } & Beams & W24x94 & W24x86 & $\mathrm{W} 24 \times 76$ & W18x60 \\
\hline & Columns & - & W14x176 & W14x176 & W14x109 \\
\hline \multirow[t]{2}{*}{ VDMF } & Beams & - & W18x86 & W18x65 & W18x60 \\
\hline & Columns & - & W14x145 & W14x145 & W14x99 \\
\hline \multirow[t]{3}{*}{$\mathrm{SCBF}$} & Beams & - & W27x84 & W30x99 & W36x150 \\
\hline & Columns & - & W14x176 & $\mathrm{W} 14 \times 176$ & W14x109 \\
\hline & Braces & - & HSS $12 \times 12 \times 0.625$ & HSS 10x10x0.625 & HSS $8 \times 8 x 0.5$ \\
\hline \multirow[t]{4}{*}{ BI-OCBF } & Beams & W24x94 & W24x84 & $\mathrm{W} 24 \times 76$ & W18x60 \\
\hline & Columns & - & $\mathrm{W} 12 \times 72$ & W12x72 & W12x72 \\
\hline & Braces & - & HSS8x8x0.625* & HSS $8 x 8 x 0.5$ & HSS6x6x0.625 \\
\hline & & & HSS6x6x0.375 & & \\
\hline \multirow[t]{3}{*}{ BRBF } & Beams & - & W18x86 & W18x86 & W18x86 \\
\hline & Columns & - & $\mathrm{W} 12 \times 120$ & $\mathrm{~W} 12 \times 120$ & W12x96 \\
\hline & Braces & - & 400 kips & 300 kips & 200 kips \\
\hline \multirow[t]{3}{*}{ BI-BRBF } & Beams & W24x94 & W18x86 & W18x86 & W18x86 \\
\hline & Columns & - & W12x96 & W12x96 & W12x96 \\
\hline & Braces & - & 250 kips $^{*}$ & 200 kips & 150 kips \\
\hline
\end{tabular}

*External Brace, ${ }^{* *}$ Internal Brace 
The SMRF was designed with a response modification factor (R) of 8 and an interstory drift limit of $2.5 \%$, and utilized reduced beam sections (prequalified beam-to-column connections). The enhanced design of SMRF (i.e, SMRFe) utilized larger sections for beams and columns to limit interstory drifts to $1 \%$. Compared to SMRF, an isolated IMRF was designed utilizing lower R factor (1.69) and drift limit (1.5\%). It uses simpler connection details and does not require a strong column-weak girder design approach. The isolation system utilized triple pendulum (TP) friction bearings, 24 in. in diameter, designed to accommodate displacements expected to occur at Maximum Considered Earthquake (MCE)-level shaking. Characteristics of these isolators, designated as ID, are given in Table 2. The enhanced BI-IMRF (i.e., BI-IMRFe) utilized larger isolators (30 in. in diameter) which reduced design forces by about $33 \%$ through the increase of the effective period of the isolation system by $40 \%$ (designated as IDe in Table 2). The SCBF and BRBF utilized chevron configuration of braces and were designed with R factors of 6 and 8, respectively, and interstory drift limit of $2.5 \%$. Compared to a SCBF and BRBF, the isolated OCBF and BRBF were designed utilizing lower R factors (1.22 and 2, respectively) and drift limit (1.5\%). To increase the robustness of the braces under the near-fault ground shaking, the braces of the OCBF were selected to have 1.5 to 2 times larger area than what is minimally needed. An alternative configuration of braces was used for the isolated OCBF and BRBF in an attempt to minimize tensile forces and uplift in the bearings. They utilized the same isolation system as BI-IMRF. The VDMF was designed for $0.75 \%$ of the seismic base shear and R factor of 8 . To limit interstory drifts to $2.5 \%$, dampers of VDMF had a stiffness of $2000 \mathrm{kips} / \mathrm{in}$., viscous damping of $32 \mathrm{kip} /$ (in./s), and velocity exponent of 0.5 . The enhanced design of VDMF utilized larger dampers that had a viscous damping of $135 \mathrm{kip} /(\mathrm{in} . / \mathrm{s})$ at first two stories and $35 \mathrm{kip} /(\mathrm{in} . / \mathrm{s})$ at the third story to limit interstory drifts to $1 \%$, which is a common engineering practice.

\subsection{Ground motion selection}

The ground motions used in the analyses are adopted from Baker et al. [4]. Forty ground motion records were selected for a site in Oakland, CA, to represent the ground motion hazard at each of three hazard levels: $2 \%, 10 \%$, and $50 \%$ probabilities of exceedence in 50 years (referred to as $2 \%$ in 50-year, $10 \%$ in 50-year, and 50\% in 50-year). These ground motions were selected and scaled to match the uniform hazard spectrum and its variance associated with the causal events for the Oakland site. Although uniform hazard spectrum cannot be interpreted as the response spectrum associated with any single ground motion, such selection of ground motions has the advantage that their amplitude at any given period has approximately the same probability of exceedence. For this comparative study, this is a useful property as a single set of ground motions can be used to analyze structures sensitive to

Table 2: Isolation system parameters.

\begin{tabular}{lllll}
\hline & \multicolumn{3}{l}{ * DBE } & $* * \mathrm{MCE}$ \\
\cline { 2 - 5 } Isolator properties & ID & IDe & ID & IDe \\
\hline Effective period & $2.77 \mathrm{sec}$ & $3.95 \mathrm{sec}$ & $3.07 \mathrm{sec}$ & $4.35 \mathrm{sec}$ \\
Effective damping & $24.2 \%$ & $22.9 \%$ & $15.8 \%$ & $15.1 \%$ \\
Isolator displacement & $12.7 \mathrm{in}$. & $16.1 \mathrm{in}$. & $24.3 \mathrm{in}$. & $30 \mathrm{in}$. \\
\hline
\end{tabular}

*Design basis earthquake, ${ }^{* *}$ Maximum considered earthquake 


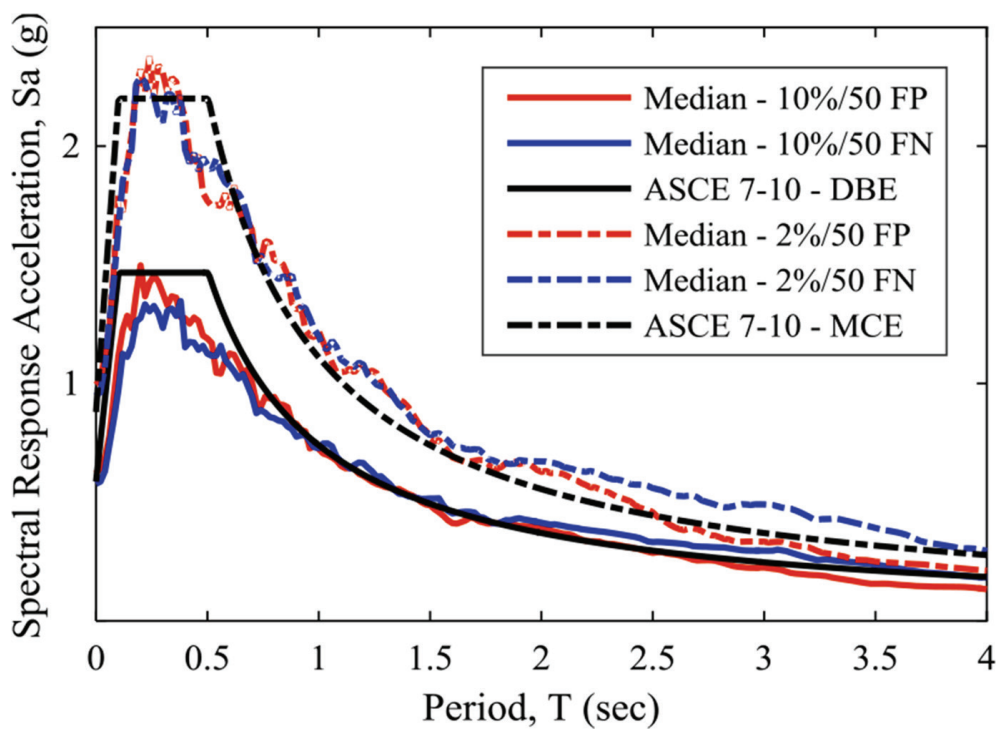

Figure 2: Comparison of code DBE and MCE spectra with the median pseudo-accelerations for the fault-normal and fault-parallel components of the 10\% in 50-year and $2 \%$ in 50-year hazard level events used in analysis.

excitation at differing periods with ground motions that are comparably 'intense' in their excitation of each building. Figure 2 highlights agreement between spectra for the code design basis earthquake (DBE) and MCE and the median pseudo-acceleration response spectra for the fault parallel (FP) and fault normal (FN) components of the 10\% in 50-year and $2 \%$ in 50-year hazard level events.

\subsection{Numerical models and methods}

To simplify the analysis for this study, time history analyses were performed on appropriately modeled two-dimensional (2D) frames. The lateral load resisting frames described above are located only on the perimeter of the building. Gravity-load-only type connections were used elsewhere in the structure. Numerical modeling assumptions are described below:

1. Half of the lateral floor mass was assigned at each floor of the 2D frame, equally distributed among all nodes of that floor.

2. Floor slabs were assumed to be axially inextensible.

3. P- $\Delta$ effects from the gravity columns were taken into account by using a single leaning column [10].

4. The effects of large deformations of beam and column elements were accounted for utilizing $\mathrm{P}-\Delta$ nonlinear geometric transformation.

5. The frames were subjected to two horizontal components of ground motion (one at a time).

The numerical model was implemented in OpenSees [5]. Centerline models were used for all systems. Beams of the SMRF utilized a reduced beam section (RBS) and were modeled using 
a series of elastic elements and concentrated plastic hinges, with stiffness of the elastic beam and initial stiffness of the plastic hinges modified as suggested by Ibarra and Krawinkler [11]. Plastic hinges were defined using zero-length elements (rotational springs). The hinge moment-rotation relationship was defined using Hysteretic Material of OpenSees. The moment-rotation relationships for RBS connections were developed based on recommendations from PEER/ATC [12], calibrated to closely resemble experimental results for RBS connection tests performed by Uang [13].

Columns of the SMRF as well as beams and columns of all other systems considered in this study were modeled utilizing two element types. The portions of beams and columns along the clear element length were modeled utilizing force-based beam-column elements of OpenSees, which accounts for the distribution of plasticity along the element. Sections were discretized into fibers. The Menegotto-Pinto hysteretic model was used to model behavior of steel fibers. Low-cycle fatigue failure of beams and columns was accounted for by using an OpenSees fatigue model that has been well calibrated for I-sections [14]. Panel-zone regions of beam-column connections were modeled with elastic elements. Braces of the SCBF, OCBF, and BRBF were modeled as suggested by Uriz and Mahin [14]. Gusset plate regions of braced frame connections were modeled with elastic elements. Viscous dampers of VDMF were modeled utilizing two node link elements in conjunction with ViscouseDamper Material of OpenSees.

For the isolated systems, isolators were modeled with zero-length elements (horizontal springs), one beneath each column of the structural frame. The bearing model represented the sum of the properties of all building isolators divided by two (number of lateral-load resisting frames in one direction) and divided by the number of columns in one frame. Vertical displacements and rotations at the top and the bottom of isolators were assumed to be fixed. To represent hysteretic behavior of bearings, tri-linear models were used. Yield points and equivalent periods of the tri-linear bearing models for the two isolation designs are given in Table 3.

Damping was assigned to the frames based on PEER/ATC [12] recommendations. The damping was modeled utilizing Rayleigh damping model and damping ratio of $3 \%$ for all lateral load-resisting systems. For the fixed-base building, mass and tangent stiffness proportional Rayleigh coefficients were calculated based on two periods. The first $\left(T_{1}\right)$ and third $\left(T_{3}\right)$ periods were selected for the 50\% in 50-year hazard level, and $1.5 T_{1}$ and $T_{3}$ for the $10 \%$ in 50 -year and $2 \%$ in 50-year hazards. The first period was elongated 1.5 times to account for the change in period due to the nonlinear deformations of the system. For the isolated building, the damping was assumed to be proportional only to the tangent stiffness of the structure as suggested by Hall [15]. The stiffness-proportional damping was calculated from the fundamental period of the structure $T_{1}$ for the $50 \%$ in 50-year hazard, and $T_{\text {eff }}$ for the $10 \%$ in 50 -year and $2 \%$ in 50-year hazards, where $T_{\text {eff }}$ is the effective fundamental period of the seismically isolated structure (Table 2). Viscous damping contributions associated with

Table 3: Yield points and equivalent periods of the tri-linear bearing models of ID and IDe designs.

\begin{tabular}{llllllll}
\hline Bearing & \multicolumn{2}{l}{ 1st branch } & \multicolumn{3}{l}{ 2nd branch } & 3rd branch \\
\cline { 2 - 7 } Design & $\mathrm{d}_{1}$ [in.] & $\mathrm{V}_{1} / \mathrm{W}$ & $\mathrm{T}_{1}$ [sec] & $\mathrm{d}_{2}$ [in.] & $\mathrm{V}_{2} / \mathrm{W}$ & $\mathrm{T}_{2}$ [sec] & $\mathrm{T}_{3}$ [sec] \\
\hline $\mathrm{ID}$ & 2.18 & 0.08 & 1.75 & 6.64 & 0.13 & 3.09 & 4.0 \\
$\mathrm{IDe}$ & 0.82 & 0.03 & 2.0 & 5.08 & 0.06 & 3.82 & 5.0 \\
\hline
\end{tabular}


stiffness were based on the stiffness of elements used to model the lateral-load resisting frames except for: (1) elements of the leaning column; (2) highly rigid truss elements that link the frame and leaning column; and (3) zero-length elements used to model beam plastic hinges of SMRF and bearings of BI-IMRF. Because the stiffness of the elastic beam elements of SMRF was modified, the stiffness proportional damping coefficients used with these elements were also modified (following Zareian and Medina [16]).

\subsection{Loss models}

Two loss metrics were used to assess the performance of considered structural systems: repair cost as a percentage of the building replacement cost and repair time. The probable repair costs and repair time were determined for each structural system at each hazard level utilizing the FEMA P-58 computer software Performance Assessment Calculation Tool (PACT) [6]. To account for the many uncertainties affecting calculation of seismic performance, the FEMA P-58 methodology uses a Monte Carlo procedure [3]. Loss modeling with PACT consists of three stages:

1. The user first inputs basic building information, such as replacement cost, occupancy type, footprint, and story height;

2. The user then defines the type and quantity of structural and non-structural components; and

3. Computed engineering demand parameters (EDPs) (maximum story drifts, maximum absolute floor horizontal acceleration, and peak residual story drifts) are input for each ground motion at each hazard level in each planar direction.

The type and quantities of structural components stem from the structural design (Table 1), while the type and quantities of non-structural components for a commercial building were determined using the normative quantities recommended by FEMA P-58 [3]. In PACT, each building component is associated with a fragility curve that correlates EDPs to the probability of that item reaching a particular damage state. The component's damage is then related to a repair cost and repair time utilizing consequence functions. The repair costs for all components of the building at one hazard level are then summed for each realization to obtain the cumulative distribution function of the repair cost for that hazard level. To estimate the cumulative distribution function of the repair time for a specified hazard level, the repair times of components along with their damage states and number of damaged units were used in conjunction with the repair time model developed by Terzic et al. [7]. Repair schedule and labor allocations were adopted from a case study of a three-story building by Yoo [17].

\section{COMPARISON OF STRUCTURAL RESPONSES}

While numerous parameters need to be considered to fully evaluate structural response, it is common to correlate performance to EDPs based on interstory drifts (ISD), floor accelerations, and residual interstory drifts. By comparing the medians of the absolute maximum responses of these EDPs for the three hazard levels considered, the relative performance characteristics of the systems studied herein can be assessed.

Compared to the SMRF, the VDMF and BRBF designed based on code-minimum requirements are effective in reducing acceleration demand at all considered hazard levels but have significantly higher median ISD demands at higher hazard levels than any other system considered in this study (Fig. 3). With the median ISD approaching $4 \%$ at the $2 \%$ in 50 -year 

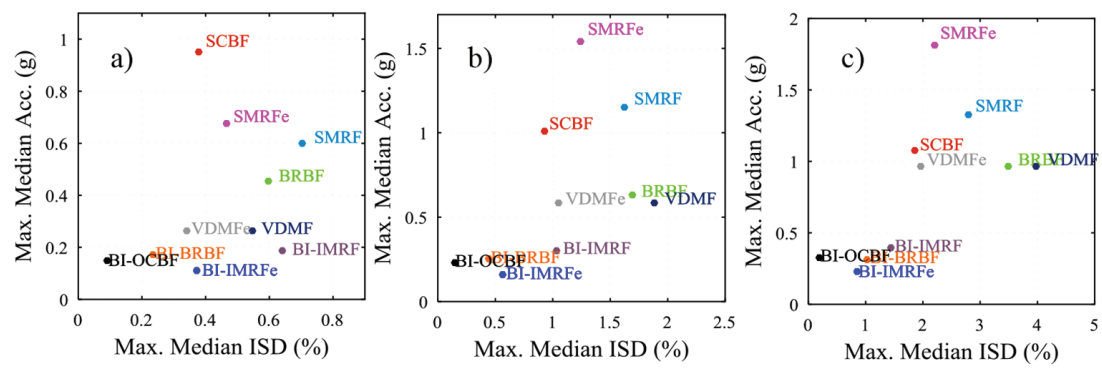

Figure 3: Maximum median interstory drift (ISD) vs. maximum median floor acceleration for the considered systems for three hazard levels: a) 50\% in 50-year, b) $10 \%$ in 50 -year, and c) $2 \%$ in 50-year.

hazard level, VDMF and BRBF may not be able to provide structural integrity after this level of shaking. By comparison, the enhanced viscously damped moment frame, VDMFe, achieves 30-50\% ISD reduction relative to SMRF across different hazard levels through utilization of larger dampers, therefore anticipating smaller repair losses. The enhanced configuration of the moment frame, SMRFe, although effective in reducing median ISD (21-37\%), amplifies floor accelerations (30-50\%), not necessarily resulting in loss reduction. Lastly, the SCBF has smaller drifts and accelerations (except for 50\% in 50-year hazard) than SMRF which should result in less pronounced damage to non-structural components but more structural damage due to the early yielding of braces (at a median ISD of $0.35 \%$ ) relative to the beams of a moment resisting frame (at a median ISD of $1.00 \%$ ).

Base-isolation substantially reduces acceleration and also drifts in both, moment resisting and braced frames at all hazard levels (Fig. 3). From the systems considered in this study, the BI-OCBF has the smallest EDPs as the isolation system substantially reduces maximum median ISDs $(63 \%, 78 \%$, and $83 \%)$ and maximum median floor accelerations $(84 \%, 79 \%$, and $70 \%$ ) across all three hazard levels. The BI-BRBF follows next with the comparable level of efficiency in reducing both, the ISDs and the floor accelerations. By comparison, BI-IMRF is equally effective in reducing the floor accelerations $(69 \%, 73 \%$, and $69 \%)$ but not as effective in reducing the ISDs $(9 \%, 35 \%$, and $47 \%)$. The enhanced system, BI-IMRFe, achieves more pronounced reduction of the ISDs $(47 \%, 63 \%$, and $67 \%)$ as it utilizes larger isolators relative to BI-IMRF.

Figure 4 shows median residual ISDs, demonstrating none or negligible residual drifts at $50 \%$ in 50-year hazard level. While the isolated systems do not experience any residual drift at the $10 \%$ in 50-year hazard level, all fixed-based system except from BRBF $(0.48 \%)$ have small median residual drifts, permitted by the code of the construction practice $(<0.2 \%)$. At the $2 \%$ in 50-year hazard level, the BI-OCBF and BI-IMRFe are the only systems with no residual ISD. At this level of excitation, the median ISD is very high for $\operatorname{VDMF}(1.22 \%)$ and BRBF $(0.95 \%)$ requiring building replacement, and high for SMRF $(0.59 \%)$ requiring structural realignment or strengthening [3].

\section{LOSS EVALUATION}

Two loss metrics used to assess the performance of considered structural systems: repair cost as a percentage of the building replacement cost (i.e., loss ratio) and repair time are presented in Figs 5-8. The fixed base systems have significantly greater median repair cost and repair time than the isolated systems at all considered hazard levels. The best performing fixed-base 

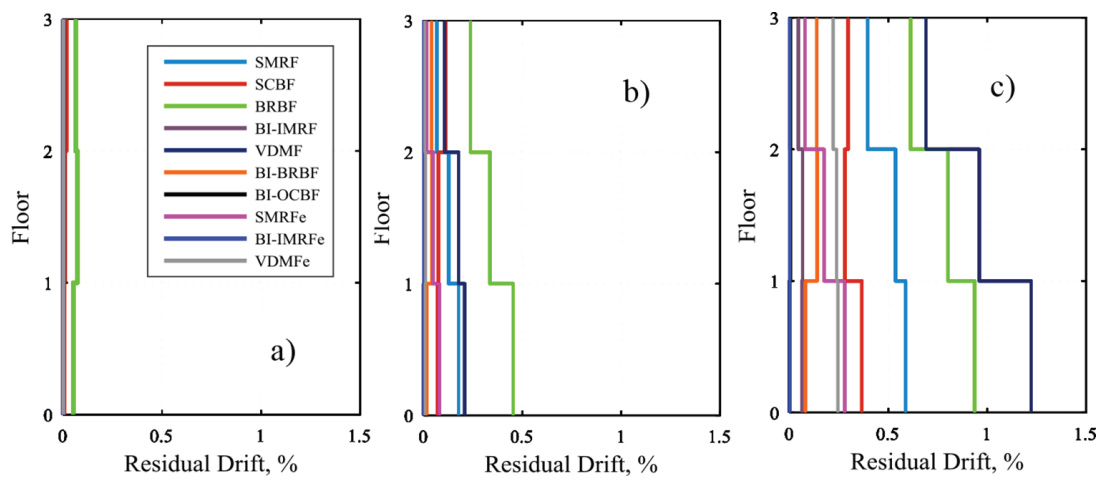

Figure 4: Median residual interstory drifts for the considered systems for three hazard levels: a) $50 \%$ in 50 -year, b) $10 \%$ in 50 -year, and c) $2 \%$ in 50 -year.

system is VDMFe with the median loss ratio of $10 \%$ and median repair time of 60 days under the strongest hazard considered. In case of the base isolated systems, the best performer is BI-OCBF with the median loss ratio of $0.8 \%$ and median repair time of 2 days under the strongest hazard considered. The median loss ratio (Fig. 5) of the fixed base systems is in the range from $0.3 \%(\mathrm{VDMFe})$ to $3 \%(\mathrm{SCBF})$ at $50 \%$ in 50- year hazard, 3\% (VDMFe) to $6 \%$ (SMRFe) at $10 \%$ in 50-year hazard, and $10 \%$ (VDMFe) to $14 \%$ (SMRF) at $2 \%$ in 50 -year hazard with VDMF and BRBF requiring replacement. The median loss ratio of the base-isolated systems is very small at all hazard level, being smaller than $0.15 \%, 1 \%$, and $5 \%$ for $50 \%, 10 \%$, and $2 \%$ in 50-year hazards, respectively.

90th percentile loss ratios (Fig. 6) of the fixed base systems are several magnitudes higher than their median losses reaching 6\%, 13\%, and 100\% (replacement of all systems) for the

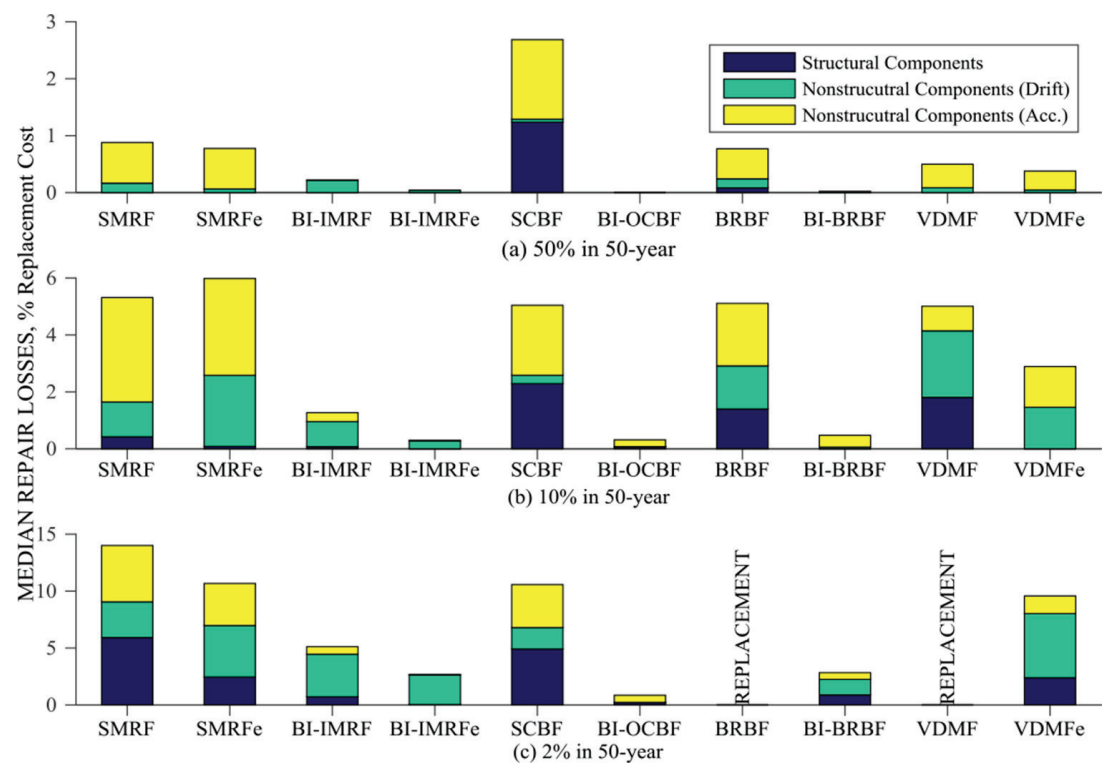

Figure 5: Median repair losses as a $\%$ of replacement cost for the considered systems and the three hazard levels. 


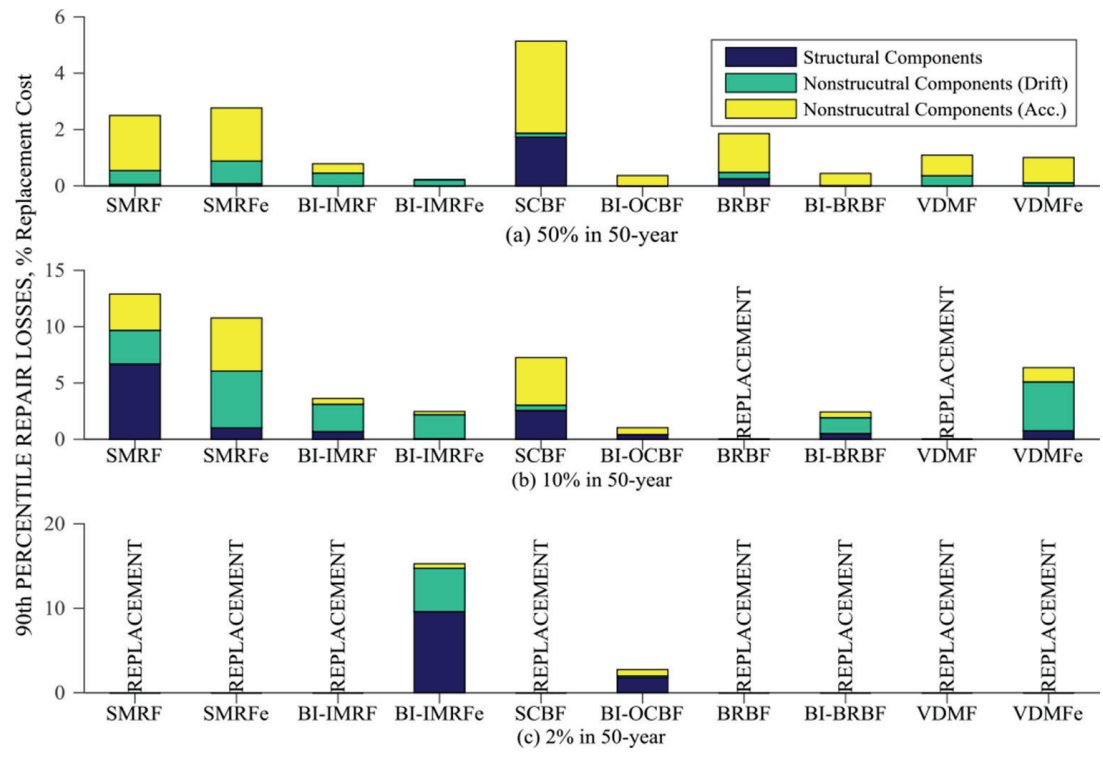

Figure 6: 90th percentile repair losses as a \% of replacement cost for the considered systems and the three hazard levels.

$50 \%, 10 \%$, and $2 \%$ in 50-year hazards, respectively, with BRBF and VDMF requiring replacement even at $10 \%$ in 50-year hazard. For the base isolated systems, these losses are smaller reaching $0.8 \%, 4 \%$, and $12 \%$ for the $50 \%, 10 \%$, and $2 \%$ in 50-year hazards, respectively, with BI-IMRF and BI-BRBF requiring replacement at $2 \%$ in 50-year hazard.

The median repair time (Fig. 7) of the fixed base systems has a larger spread than the loss ratio and is in the range from 3 days (VDMFe) to 55 days (SCBF) at 50\% in 50-year hazard,

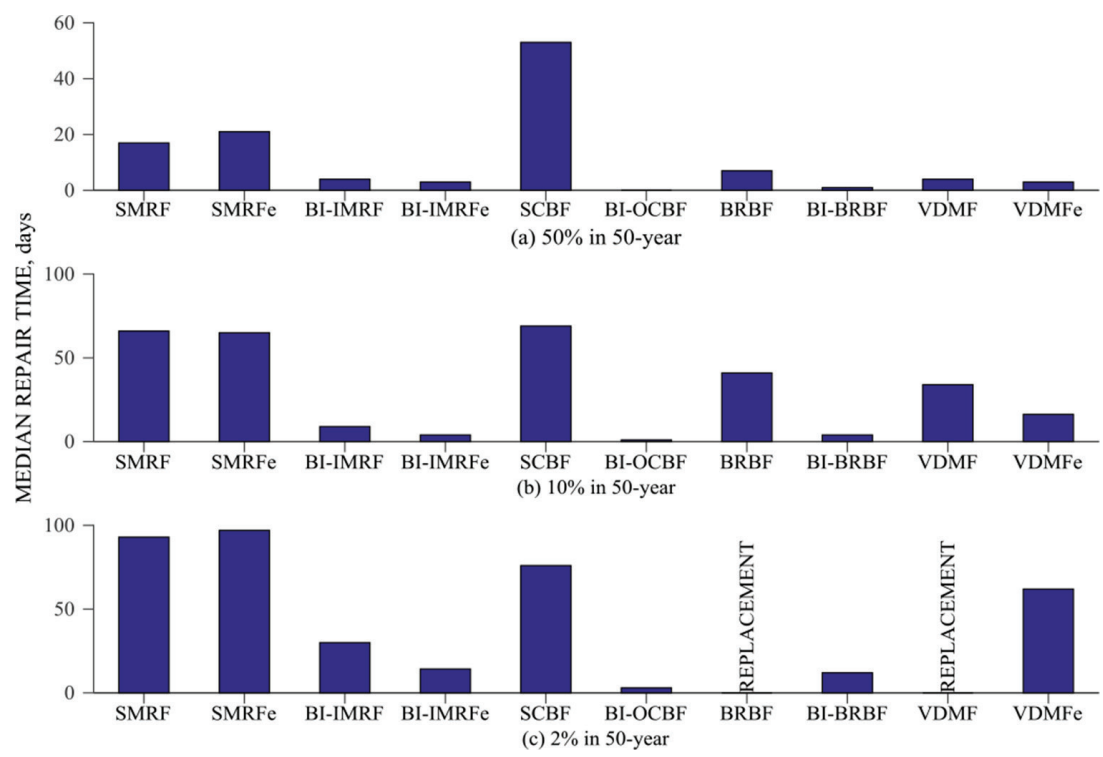

Figure 7: Median repair time for the considered systems and the three hazard levels. 


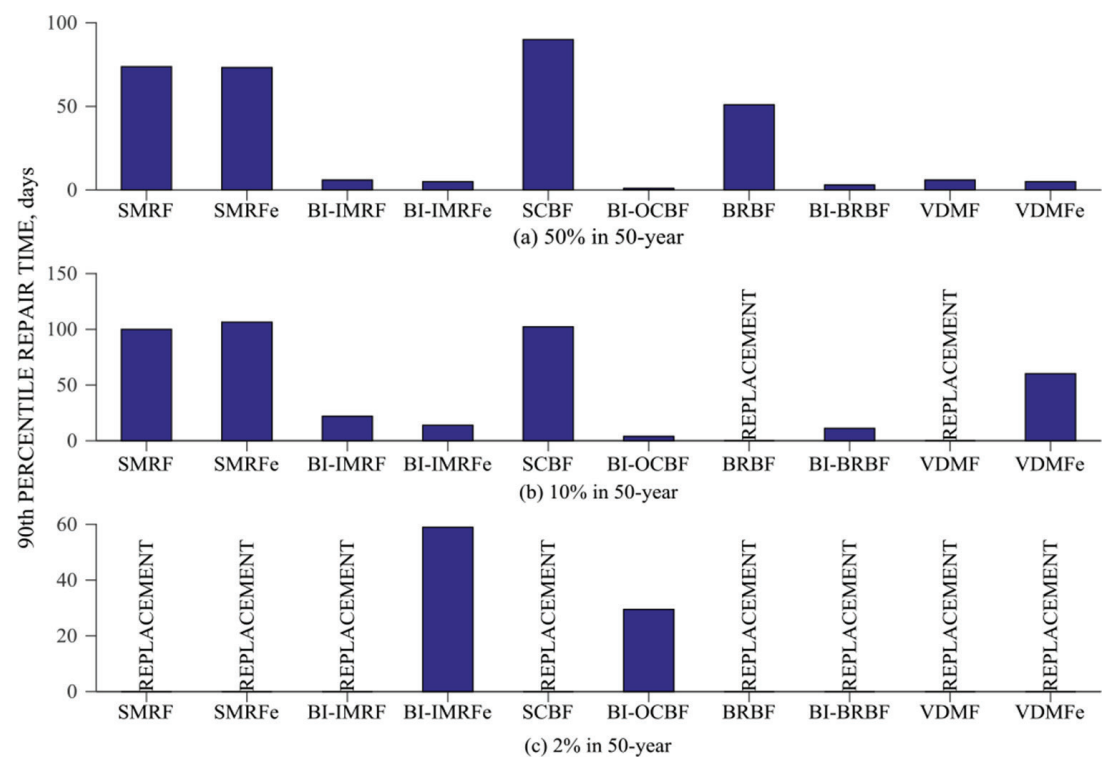

Figure 8: 90th percentile repair time for the considered systems and the three hazard levels.

20 days (VDMFe) to 70 days (SCBF) at 10\% in 50-year hazard, and 75 days (VDMFe) to 100 days (SMRFe) at $2 \%$ in 50-year hazard with the exception of systems that require replacement. The median repair time of the base-isolated systems is very small at all hazard level, being smaller than 3, 8, and 20 days for 50\%, 10\%, and $2 \%$ in 50-year hazards, respectively.

90th percentile repair times (Fig. 8) of the fixed base systems are several magnitudes higher than their median values reaching 95, 110, and 720 days (replacement time) for the $50 \%, 10 \%$, and $2 \%$ in 50-year hazards, respectively. For the base isolated systems, these losses are smaller reaching 8, 20, and 60 days for the 50\%, 10\%, and 2\% in 50-year hazards, respectively, with BI-IMRF and BI-BRBF requiring replacement at $2 \%$ in 50-year hazard.

\section{CONCLUSIONS}

Current U.S. building codes are oriented toward preserving lives and preventing collapse rather than minimizing economic loss. As shown in this study that considers three-story steel commercial building, performance of the seven considered structural systems designed to meet the minimum and beyond code requirements ranged from poor to superior. Considering the range of hazard levels, from the systems designed to meet the minimum code requirements the least desirable are the special concentrically braced frame with 55 days of repair time at 50\% in 50-year hazard level associated with the brace buckling; and the buckling restrained braced frame along with the viscously damped moment frame which at stronger intensities of shaking exhibit substantial residual interstory drifts resulting in a great probability of deeming the building irreparable. Overall, the fixed base systems had significantly greater median repair cost and repair time than their isolated configurations at all considered hazard levels. The best performing fixed-base system is an enhanced viscously damped moment frame reaching the median loss ratio of $10 \%$ and median repair time of 60 days under the $2 \%$ in 50-year hazard level. In case of the base isolated configurations, the best 
performer is the ordinarily concentrically braced frame reaching the median loss ratio of $0.8 \%$ and median repair time of 2 days under the $2 \%$ in 50-year hazard level. The study also demonstrated that an investment into a stronger and stiffer moment frame may not result in loss savings, while an investment into larger dampers or isolators can yield substantial savings. It is thus recommended to utilize holistically oriented performance-based earthquake evaluation methodologies in seismic design to identify the proportions and details of the system that can improve the overall performance of a structure.

\section{ACKNOWLEDGEMENTS}

I authors acknowledge financial support for this work from the Pacific Earthquake Engineering Research Center under the projects 2002-NCEEVT. We are grateful for the Applied Technology Council providing the latest release of the PACT software application. The conclusions, observations, and findings presented herein are those of the authors and not necessarily those of the sponsors.

\section{REFERENCES}

[1] Miranda, E., Mosqueda, G., Retamales R. \& Pekcan, G., Performance of nonstructural components during the 27 February 2010 Chile earthquake. Earthquake Spectra, 28(S1), pp. S453-S471, 2012.

https://doi.org/10.1193/1.4000032

[2] Miranda, E. \& Aslani, H., Probabilistic response assessment for building specific loss estimation. Pacific Earthquake Engineering Research Center, University of California, Berkeley, CA, USA, 2003. Report PEER 2003/03.

[3] FEMA. Next-generation methodology for seismic performance assessment of buildings. Prepared by the Applied Technology Council for the Federal Emergency Management Agency, Report No. FEMA P-58, Washington, DC., 2012.

[4] Baker, J.W., Lin, T., Shahi, S.K. \& Jayaram, N., New ground motion selection procedures and selected motions for the PEER transportation research program. Pacific Earthquake Engineering Research Center, University of California, Berkeley, CA, USA, 2011. Report PEER 2011/03.

[5] McKenna, F. \& Fenves, G.L. Open system for earthquake engineering simulation (OpenSees). PEER, University of California, Berkeley, CA, 2004.

[6] Applied Technology Council (ATC). Performance assessment computation tool (PACT v3.0.3). Applied Technology Council, Redwood City, CA, 2012.

[7] Terzic, V., Yoo, D. \& Aryan, A. H., Repair time model for buildings considering the earthquake hazard. SEAOC Convention, Maui, HI, 2016.

[8] American Society of Civil Engineers. Minimum design loads for buildings and other structures. ASCE 7-10, ASCE, Reston, VA, 2010.

[9] Structural Design Calculations and Drawings, Forell/Elessesser Engineers, available at: http://www.neng.usu.edu/cee/faculty/kryan/NEESTIPS/PBEE_study.html. (accessed March 15, 2015).

[10] Gupta, A. \& Krawinkler, H., Seismic demands for performance evaluation of steel moment resisting frame structures. Stanford University, Stanford, CA, pp. 26-28, 1999.

[11] Ibarra L.F. \& Krawinkler, H., Global collapse of frame structures under seismic excitations (Rep. No. TB 152), The John A. Blume Earthquake Engineering Center, Stanford University, Stanford, CA, 2005. 
[12] PEER/ATC. Modeling and acceptance criteria for seismic design and analysis of tall buildings (PEER/ATC-72-1). prepared by the Applied Technology Council in cooperation with PEER, Redwood City, CA, 2010.

[13] Uang, C.M., Cyclic response of RBS moment connections: loading sequence and lateral bracing effects. University of San Diego, San Diego, California, 2000. (Report No. SSR99/13)

[14] Uriz, P. \& Mahin, S.A., Toward earthquake-resistant design of concentrically braced steel-frame structures. Pacific Earthquake Engineering Research Center, University of California, Berkeley, CA, USA, 2008. (Report PEER 2008/08.)

[15] Hall, J.F., Problems encountered from the use (or misuse) of Raleigh damping. Earthquake Engineering and Structural Dynamics, 35(5), pp. 525-545, 2005. https://doi.org/10.1002/eqe.541

[16] Zareian, F. \& Medina, R.A., A practical method for proper modeling of structural damping in inelastic plane structural systems. Computers \& Structures, 88(1-2), pp. $45-53,2010$.

https://doi.org/10.1016/j.compstruc.2009.08.001

[17] Yoo, D.Y., Repair time model for different builidnig sizes considering the earthquake hazard. Master Thesis, California State University Long Beach, CA, 2016. 